\title{
Diabetes Mellitus in Very Elderly Russian Patients with Coronary Artery Disease
}

\author{
S. V. Topolyanskaya', T. M. Kolontai ${ }^{2}$, O. N. Vakulenko², L. I. Dvoretski ${ }^{1}$ \\ ${ }^{1}$ Department of Hospital Therapy N2, First Moscow State Medical University (Sechenov University), Moscow, Russia \\ ${ }^{2}$ War Veterans Hospital N3, Moscow, Russia \\ Email: sshekshina@yahoo.com
}

How to cite this paper: Topolyanskaya, S.V., Kolontai, T.M., Vakulenko, O.N. and Dvoretski, L.I. (2020) Diabetes Mellitus in Very Elderly Russian Patients with Coronary Artery Disease. Journal of Biosciences and Medicines, 8, 167-177.

https://doi.org/10.4236/jbm.2020.89014

Received: August 24, 2020

Accepted: September 19, 2020

Published: September 22, 2020

\begin{abstract}
Background: Conflicting data are available on prevalence and characteristics of diabetes mellitus in very elderly patients and centenarians; therefore, we evaluated features of this pathology in patients with coronary artery disease (CAD) over 75 years old. Material and Methods: 580 patients with CAD over 75 years old were enrolled in the study on the prevalence of diabetes mellitus. 190 patients with CAD and diabetes mellitus were included in the cross-sectional study of the diabetes mellitus characteristics in old age: 153 very elderly patients (mean age $-85.7 \pm 4.7$ years) —in the main group, $37 \mathrm{pa}$ tients $<70$ years old-in the comparison group. Toassess the condition of patients, standard clinical and laboratory methods for coronary artery disease and diabetes mellitus were used. 24-hour plasma glucose profile and hemoglobin Alc (HbAlc) level were evaluated in all patients with diabetes mellitus. Results: Diabetes mellitus or impaired glucose tolerance was found in $22.2 \%$ of very elderly patients with CAD. Glucose levels in very elderly diabetic patients were lower at all time points than in patients $<70$ years old. The largest differences were recorded for the blood glucose concentration at 6 a.m. ( $\mathrm{p}=$ 0.00005). Glucosuria was registered in $29.7 \%$ of patients aged $51-69$ years, while among elderly patients-in $11.1 \%(\mathrm{p}=0.004)$. The mean levels of $\mathrm{HbA} 1 \mathrm{c}$ were $7.3 \%$ and $8.7 \%$, respectively $(\mathrm{p}=0.01)$. Correlation analysis revealed negative correlation between the age of patients and the glucose level $(\mathrm{r}=-0.4, \mathrm{p}=0.00002$-for $6 \mathrm{AM}$ glucose $)$. The mean body mass index in very elderly patients was $30.8 \pm 5.8 \mathrm{~kg} / \mathrm{m}^{2}$, in patients $<70$ years old $-33.9 \pm$ $6.5 \mathrm{~kg} / \mathrm{m}^{2}(\mathrm{p}=0.03)$. Significant differences between the groups of very elderly and younger patients were registered in terms of triglycerides (1.65 and $3.57 \mathrm{mmol} / \mathrm{L}$, respectively, $\mathrm{p}<0.00001)$, HDL-cholesterol $(1.16$ and 0.87 $\mathrm{mmol} / \mathrm{L}$, respectively, $\mathrm{p}=0.03$ ) and atherogenic index (3.45 and 6.73 , respectively, $\mathrm{p}=0.002)$. Conclusion: The study results indicate that diabetes mellitus is often diagnosed in very elderly patients with CAD. In very elderly pa-
\end{abstract}


tients, lower values of blood glucose, hemoglobin Alc and glucosuria are recorded, compared with younger patients with diabetes mellitus.

\section{Keywords}

Diabetes Mellitus, Coronary Artery Disease, Glucose, Hemoglobin A1c, Very Elderly

\section{Introduction}

Diabetes mellitus is a chronic metabolic disease caused by hyperglycemia and increased levels of hemoglobin A1c. Chronic hyperglycemia leads to damage and failure of various organs and systems-primarily heart, eyes, kidneys and peripheral nerves, to the development of micro- and macroangiopathy. Pathological changes in glucose metabolism occur as a result of disorders or the insulin secretion by the pancreas, or the effect of insulin on peripheral tissues (insulin resistance), or as a result of both pathological processes [1].

Diabetes mellitus in the elderly is primarily based on insulin resistance. A decrease in insulin secretion with aging and an increase in life expectancy also play a role. In addition, sarcopenic obesity, which develops in the majority of the elderly and aggravates insulin resistance, is also important. The formation of diabetes mellitus is influenced by both a decrease in physical activity and nutritional disorders that characterize the modern lifestyle. According to modern concepts, other factors are also involved in the development of diabetes mellitus in the elderly. So, in recent studies, the role of arginine vasopressin and its c-terminal fragment called copeptin, which reduces the sensitivity of peripheral tissues to insulin, has been demonstrated. Arginine vasopressin also affects liver glycogenolysis and glucagon secretion [2] [3].

Vitamin D deficiency becomes an additional pathogenic factor in the elderly. According to some authors, vitamin D deficiency may be a link between insulin resistance, osteoporosis, obesity, diabetes mellitus and cognitive impairment, especially Alzheimer's disease. There is experimental evidence that vitamin D inhibits fat accumulation, protects pancreatic cells, stimulates insulin synthesis and reduces hunger [4] [5]. In addition, deficiencies in other micronutrients (in particular magnesium and potassium) should be considered when diabetes occurs in the elderly and poor glycemic control occurs [6].

The prevalence of diabetes mellitus is increasing all over the world, becoming an epidemic with increasing social and economic burden. According to the International Diabetes Federation, 463 million adults in the world suffered from diabetes in 2019. It is possible that 700 million adults will be diagnosed with diabetes mellitus by 2045 [7]. The prevalence of diabetes mellitus is significantly higher in the elderly. On average, about $20 \%$ of older age groups suffer from diabetes mellitus; in about the same number of people, diabetes remains undiagnosed. Data on prevalence of diabetes in old age range from $18 \%$ to $33 \%$; such a 
spread may reflect age differences, lifestyle characteristics, and genetic characteristics of the studied populations. Thus, according to American authors, almost 8 out of 10 elderly US residents have some form of glucose metabolism disorders when performing various tests [8]. At the same time, almost $30 \%$ of elderly people reveal impaired glucose tolerance, which, in turn, predisposes to the formation of diabetes mellitus. Thus, diabetes mellitus is one of the most significant problems of modern medicine [2] [8] [9].

Conflicting medical literature data on the prevalence and features of diabetes mellitus in elderly patients served as the basis for our attempt to study the characteristics of diabetes mellitus in patients with coronary artery disease over 75 years old and compare them with younger patients with coronary artery disease $(C A D)$ and diabetes mellitus.

\section{Material and Methods}

The present cross-sectional study was performed at the clinical base of the War Veterans Hospital N3 (Moscow). The study enrolled men and women $\geq 75$ years of age who were hospitalized with coronary artery disease. Diagnosis of coronary artery disease was based on: history of myocardial infarction, percutaneous coronary interventions or coronary artery bypass grafting in the past, as well as on presence of typical stable angina pectoris and estimation of pre-test probability of CAD. The main exclusion criterion was acute coronary syndrome over the past four weeks before the enrollment in the study.

To assess the condition of patients, standard clinical examination methods for coronary artery disease and diabetes mellitus were used. The level of systolic and diastolic blood pressure was measured in patients in a sitting position. The body weight and height of patients were measured, and body mass index (BMI) was calculated by the formula weight $/$ height $^{2}\left(\mathrm{~kg} / \mathrm{m}^{2}\right)$. BMI values from 18.5 to 24.9 were considered as indicators of normal body mass; BMI values between 25 and 29.9 indicated excessive body mass; obesity was diagnosed if BMI was $\geq 30 \mathrm{~kg} / \mathrm{m}^{2}$ (class I obesity-with BMI 30.0 - $34.9 \mathrm{~kg} / \mathrm{m}^{2}$, II-35.0 - $39.9 \mathrm{~kg} / \mathrm{m}^{2}$, III-with BMI $\geq 40 \mathrm{~kg} / \mathrm{m}^{2}$ ).

Standard laboratory blood and urine tests were also performed. Venous blood samples were collected between 07:00 and 08:00, after overnight fasting, for the measurement of fasting plasma glucose, total cholesterol, high-density cholesterol (HDL-cholesterol), low-density cholesterol (LDL-cholesterol), triglycerides, uric acid, creatinine, urea. Creatinine clearance was calculated using the CKD-EPI equation. 24-hour plasma glucose profile and hemoglobin A1c (HbAlc) level were evaluated in all patients with diabetes mellitus. Diabetes mellitus was defined according to the following criteria: fasting plasma glucose $\geq 7.0 \mathrm{mmol} / \mathrm{L}$ or 2-h plasma glucose in the oral glucose tolerance test $\geq 11.1 \mathrm{mmol} / \mathrm{L}$ [1].

The data were analyzed using Statistica software (version 13.0). To provide the data, descriptive statistics methods were used (mean value and standard deviation for quantitative variables; number and proportion for qualitative variables). 
The statistical significance of differences between the values was assessed by Mann-Whitney test or chi-square test (as appropriate). Correlation (using the Spearman test) and multiple regression analyses were performed among the parameters. A $p$-value of $<0.05$ was considered as statistically significant.

This study was approved by the Independent Ethical Committee of the First Moscow State Medical University (Sechenov University) ( $\left.\mathrm{N}^{\circ} 05-2017\right)$.

\section{Results}

\subsection{Prevalence of Glucose Metabolism Disorders in Very Elderly Patients with Coronary Artery Disease}

The study enrolled 580 very elderly patients with chronic coronary artery disease. Diabetes mellitus or impaired glucose tolerance was found in $22.2 \%$ of the examined patients. Comparative characteristics of the patients with diabetes mellitus or impaired glucose tolerance and without this pathology are shown in Table 1.

Table 1. Comparative characteristics of CAD patients with diabetes mellitus or impaired glucose tolerance and without these pathologies.

\begin{tabular}{|c|c|c|c|}
\hline Parameters & $\begin{array}{l}\text { Patients with diabetes } \\
\text { mellitus or impaired } \\
\text { glucose tolerance }\end{array}$ & $\begin{array}{l}\text { Patients with } \\
\text { normal glucose } \\
\text { metabolism }\end{array}$ & $\mathrm{p}$ \\
\hline Age, years & $87.3 \pm 5.2$ & $86.9 \pm 5.0$ & 0.44 \\
\hline Women & $25.3 \%$ & $74.7 \%$ & \multirow{2}{*}{0.01} \\
\hline Men & $15.5 \%$ & $84.5 \%$ & \\
\hline Coronary artery disease & $100 \%$ & $100 \%$ & NS \\
\hline Arterial hypertension & $100 \%$ & $100 \%$ & NS \\
\hline Myocardial infarction in history & $38.0 \%$ & $22.1 \%$ & 0.0003 \\
\hline Heart failure & $20.9 \%$ & $14.6 \%$ & 0.08 \\
\hline Atrial fibrillation & $38.0 \%$ & $32.0 \%$ & 0.2 \\
\hline Stroke in history & $21.7 \%$ & $15.5 \%$ & 0.1 \\
\hline Hyperuricemia & $48.7 \%$ & $36.4 \%$ & 0.01 \\
\hline Body mass index, $\mathrm{kg} / \mathrm{m}^{2}$ & $30.7 \pm 4.7$ & $28.5 \pm 5.4$ & 0.01 \\
\hline Arterial pressure syst, $\mathrm{mm} \mathrm{Hg}$ & $147.3 \pm 17.4$ & $143.0 \pm 18.8$ & 0.02 \\
\hline Arterial pressure diast, $\mathrm{mm} \mathrm{Hg}$ & $81.5 \pm 9.8$ & $79.2 \pm 10.4$ & 0.02 \\
\hline Total cholesterol, $\mathrm{mmol} / \mathrm{L}$ & $4.8 \pm 1.1$ & $4.9 \pm 1.2$ & 0.65 \\
\hline HDL-cholesterol, mmol/L & $1.2 \pm 0.3$ & $1.2 \pm 0.4$ & 0.68 \\
\hline LDL-cholesterol, $\mathrm{mmol} / \mathrm{L}$ & $2.8 \pm 0.9$ & $2.8 \pm 1.0$ & 0.62 \\
\hline Triglycerides, $\mathrm{mmol} / \mathrm{L}$ & $1.6 \pm 1.1$ & $1.4 \pm 0.7$ & 0.01 \\
\hline Atherogenic index & $3.2 \pm 1.1$ & $3.1 \pm 1.2$ & 0.64 \\
\hline Creatinine, $\mu \mathrm{mol} / \mathrm{L}$ & $104.7 \pm 24.9$ & $107.4 \pm 35.1$ & 0.41 \\
\hline Urea, $\mathrm{mmol} / \mathrm{L}$ & $7.9 \pm 2.8$ & $7.7 \pm 3.2$ & 0.46 \\
\hline Uric acid, $\mu \mathrm{mol} / \mathrm{L}$ & $361.3 \pm 113.7$ & $348.8 \pm 117.1$ & 0.32 \\
\hline
\end{tabular}




\subsection{Features of Diabetes Mellitus in Very Elderly Patients with Coronary Artery Disease}

The study of the diabetes mellitus features in very elderly patients enrolled 190 patients with coronary artery disease and with diabetes mellitus. The main group consisted of 153 very elderly patients, and the comparison group consisted of 37 patients $<70$ years of age (mean $-60.0 \pm 5.4$ years) with coronary artery disease and diabetes mellitus.

The mean age of patients in the main group was $85.7 \pm 4.7$ years (from 75 to 96 years). Most of very elderly patients enrolled in the study (63.4\%) were in the age group of 85 years and older, in the group of patients $75-79$ years there were only $16.3 \%$ of the examined subjects. The vast majority of patients in the main group were women $(84.3 \%)$. The time from the diabetes mellitus diagnosis to inclusion in the present study ranged from 0 to 40 years (mean $-11.2 \pm 8.3$ years). However, $36.3 \%$ of very elderly patients could not accurately remember the duration of diabetes mellitus. Age at the time of diabetes mellitus diagnosis ranged from 40 to 92 years (mean $-73.8 \pm 8.8$ years).

In addition to coronary artery disease and diabetes mellitus, very elderly patients enrolled in the study suffered from multiple comorbid pathologies (arterial hypertension, chronic heart failure, atrial fibrillation, stroke in history, hyperuricemia, hypothyroidism, and others). The mean body mass index in the group of very elderly diabetic patients was $30.9 \pm 5.8 \mathrm{~kg} / \mathrm{m}^{2}$ (from 17 to $50 \mathrm{~kg} / \mathrm{m}^{2}$ ). In $56.4 \%$ of these patients, the body mass index was $30 \mathrm{~kg} / \mathrm{m}^{2}$ and higher, which corresponded to obesity. Class I obesity was registered in $32.2 \%$ of very elderly patients, class II obesity-in $22.6 \%$, class III obesity had only two patients.

In the group of very elderly patients with diabetes mellitus, $5.9 \%$ of patients did not take any drugs and did not follow the strict diet, $12.4 \%$ tried not to break the diet. Insulin monotherapy was administered to $10.4 \%$ of patients, combined therapy with insulin and oral anti-diabetic medications-to $7.8 \%$ of patients. The remaining $63.5 \%$ of patients took various oral medications, most often sulfonylureas (in $38 \%$ of cases) and metformin (in $10.4 \%$ of cases), as well as their combinations (in $13.7 \%$ of cases).

24-hour blood glucose profile in very elderly patients with diabetes mellitus is presented in Table 2.

Glucosuria was found only in $11.1 \%$ of cases; the mean level of urine glucose was $1.57 \mathrm{mmol} / \mathrm{L}$ (from 1.5 to $55 \mathrm{mmol} / \mathrm{L}$ ). The mean level of $\mathrm{HbAlc}$ in very elderly patients was $7.3 \% \pm 1.4 \%$ (from $5.3 \%$ to $10.9 \%$ ).

Correlation analysis revealed negative correlation between the age of patients and the glucose level (Table 3).

When analyzing the relationships between the glycemia levels and the duration of diabetes mellitus in very elderly patients, significant positive correlation was found between the disease duration and the glucose level at 12 hours $(r=$ $0.27 ; \mathrm{p}=0.009)$ and at 9 hours p.m. $(\mathrm{r}=0.30 ; \mathrm{p}=0.009)$. Along with this, direct correlation was registered between the diabetes mellitus duration and the glucosuria level $(r=0.25 ; \mathrm{p}=0.01)$. Patients with the diabetes mellitus duration of 
Table 2. 24-hour glucose profile in very elderly patiets with diabetes mellitus.

\begin{tabular}{cccccccc}
\hline Time point & Fasting & $6 \mathrm{AM}$ & $\mathbf{9} \mathrm{AM}$ & $\mathbf{1 2}$ & 4 PM & 6 PM & 9 PM \\
\hline $\begin{array}{c}\text { Mean } \pm \mathrm{SD} \\
\text { (Min - Max }), \\
\mathrm{mmol} / \mathrm{L}\end{array}$ & $3.9 \pm 2.6$ & $5.9 \pm 1.8$ & $6.4 \pm 1.9$ & $9.2 \pm 3.5$ & $8.2 \pm 2.9$ & $7.8 \pm 2.6$ & $8.0 \pm 2.7$ \\
\hline
\end{tabular}

Table 3. Correlations between glucose metabolism indices and the age of patients.

\begin{tabular}{ccc}
\hline Index & $\mathrm{r}$ & $\mathrm{p}$ \\
\hline Fasting glucose & -0.27 & $\mathbf{0 . 0 0 0 6}$ \\
6 AM glucose & -0.4 & $\mathbf{0 . 0 0 0 0 2}$ \\
9 AM glucose & -0.31 & $\mathbf{0 . 0 0 0 0 4}$ \\
12 hr glucose & -0.09 & 0.2 \\
4 PM glucose & -0.19 & $\mathbf{0 . 0 2}$ \\
6 PM glucose & -0.14 & 0.25 \\
9 PM glucose & -02 & $\mathbf{0 . 0 1}$ \\
Glucosuria & -0.18 & $\mathbf{0 . 0 1}$ \\
HbA1c & -0.4 & $\mathbf{0 . 0 0 2}$ \\
\hline
\end{tabular}

more than 10 years had higher glycemic parameters than patients with shorter duration of the disease: at 9 hours a.m. $(7.1$ and $6.1 \mathrm{mmol} / \mathrm{L}$, respectively; $\mathrm{p}=$ 0.03 ), at 12 hours ( 10.3 and $8.1 \mathrm{mmol} / \mathrm{L}, \mathrm{p}=0.008)$, at 4 hours p.m. ( 8.8 and 7.1 $\mathrm{mmol} / \mathrm{L}, \mathrm{p}=0.01$ ) and at 9 hours p.m. ( 8.9 and $7,4 \mathrm{mmol} / \mathrm{L}, \mathrm{p}=0.02)$.

In regression analysis the most significant variables for fasting blood glucose concentration were the diabetes mellitus duration $(\beta=0.83, \mathrm{p}=0.02$-for direct relationship) and body mass index $(\beta=0.31, \mathrm{p}=0.01)$. For postprandial glyce$\mathrm{mia}$, the most significant variables were the patient's age $(\beta=-0.6, \mathrm{p}=0.0001)$ and the age of the disease onset $(\beta=-10.3, \mathrm{p}=0.01)$ (inverse relationships), as well as the diabetes mellitus duration ( $\beta=0.46, \mathrm{p}=0.0001$ ) (direct relationship).

When comparing the diabetes mellitus characteristics in very elderly patients with coronary artery disease and patients $<70$ years old, the following results were obtained. The glucose levels in very elderly diabetic patients were lower at all time points (Figure 1). The largest differences were recorded for the blood glucose concentration at 6 a.m. $(\mathrm{p}=0.00005)$. Differences in plasma glucose concentration at 12 o'clock did not reach the level of statistical significance (9.2 vs $10.6 \mathrm{mmol} / \mathrm{L}, \mathrm{p}=0.07)$. Glucosuria was registered in $29.7 \%$ of patients aged $51-69$ years, while among very elderly patients-in $11.1 \%(\mathrm{p}=0.004)$. The mean levels of $\mathrm{HbA1c}$ were $7.3 \%$ and $8.7 \%$, respectively $(\mathrm{p}=0.01)$.

Significant differences were recorded between very elderly patients and younger diabetic patients in terms of body mass index. The mean body mass index in very elderly patients was $30.8 \pm 5.8 \mathrm{~kg} / \mathrm{m}^{2}$, in patients $<70$ years old- 33.9 $\pm 6.5 \mathrm{~kg} / \mathrm{m}^{2}(\mathrm{p}=0.03)$. There were also registered significant differences between the groups of very elderly and younger patients in terms of triglycerides (1.65 


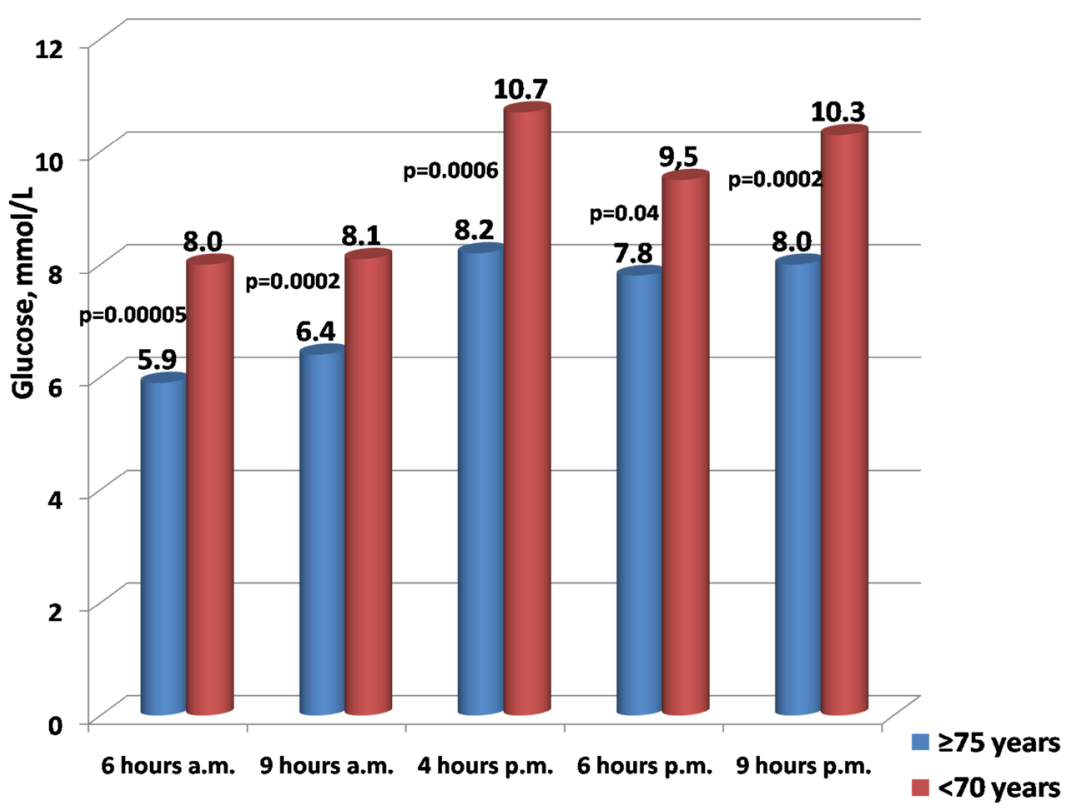

Figure 1. Plasma glucose levels in very elderly patients and patients $<70$ years old with diabetes mellitus.

and $3.57 \mathrm{mmol} / \mathrm{L}$, respectively, $\mathrm{p}<0.00001)$, HDL-cholesterol $(1.16$ and 0.87 $\mathrm{mmol} / \mathrm{L}$, respectively, $\mathrm{p}=0.03)$ and atherogenic index $(3.45$ and 6.73 , respectively, $\mathrm{p}=0.002)$. Differences in total cholesterol and LDL cholesterol did not reach the level of statistical significance $(\mathrm{p}=0.65$ and $\mathrm{p}=0.16$, respectively). At the same time, very elderly patients had higher levels of serum creatinine (103 vs $92 \mu \mathrm{mol} / \mathrm{L}, \mathrm{p}=0.02)$ and urea ( $8.2 \mathrm{vs} 5.9 \mathrm{mmol} / \mathrm{L}, \mathrm{p}=0.0001)$, as well as lower glomerular filtration rate ( $42.1 \mathrm{vs} 60.0 \mathrm{ml} / \mathrm{min}, \mathrm{p}=0.00007)$ compared with patients under 70 years of age.

\section{Discussion}

Our results indicate the significant prevalence of diabetes mellitus in very elderly patients with coronary artery disease. At the same time, we found that diabetes mellitus in older people is less severe than in younger people. Fasting plasma glucose, according to our data, was relatively low $(5.9 \mathrm{mmol} / \mathrm{L})$; however, the level of postprandial glycemia reached $9.2 \mathrm{mmol} / \mathrm{L}$. Our results are confirmed by data from other studies of glucose metabolism in elderly people [10] [11]. Since the level of fasting glycemia in elderly patients with diabetes mellitus is often within the normal range or slightly increases, the use of this test alone significantly worsens the disease diagnosis in people of this age group [11]. According to a number of authors, $35 \%-70 \%$ of elderly patients with newly diagnosed diabetes mellitus had only isolated postprandial hyperglycemia [10]. Compared to younger people, postprandial blood glucose levels increase even in relatively healthy older adults.

Glucosuria was found only in every ninth of our very elderly patients, and its level negatively correlated with age. This rare detection of glucosuria is primarily 
due to the fact that the renal threshold for glucose excretion increases with age, therefore, glucosuria is rarely detected in elderly patients with diabetes mellitus. The mean level of hemoglobin A1c in our very elderly patients was relatively low (7.3\%). As in our work, in other studies, hemoglobin A1c in patients with diabetes mellitus in old age also did not exceed $7.0 \%-7.9 \%$ on average [12] [13] [14] [15]. In a recent Chinese study involving 5770 elderly diabetic patients, it was found that the mean value of hemoglobin Alc at diagnosis was $7.9 \%$, and after a year of follow-up, this figure decreased to $6.6 \%$ [14]. The Swedish national diabetes register also found a relatively low $(6.6 \%-6.7 \%)$ level of hemoglobin A1c at the onset of diabetes mellitus in old age [16].

The optimal level of hemoglobin A1c, when there is minimal mortality in elderly patients, is in the range of $6 \%-9 \%$ [12]. The hemoglobin Alc level was within these optimal limits in the vast majority of our patients, and only in 6 patients this indicator exceeded $9 \%$. The results of our work confirm the data of a large Chinese study, in which the hemoglobin A1c level increased up to 79 years of age and then stabilized. At the same time, the frequency of an increase in hemoglobin A1c of more than $6.5 \%$ decreased with age; and there was a negative correlation between the hemoglobin A1c level and the age of patients [17] [18].

In our work, we noted a direct correlation between the duration of diabetes mellitus and the level of glycemia (especially postprandial) and glucosuria. The obtained data confirm the results of other studies, which indicate the deterioration of the diabetes mellitus control with an increase in the disease duration [19] [20]. In our observations, there was a significant increase in postprandial glycemia at all time points in those cases when the duration of diabetes mellitus exceeded 10 years; other authors have reported similar results [19] [20]. This feature of the diabetes mellitus course can be explained by the progressive impairment of insulin secretion over time, along with an increase in insulin resistance [20]. In our group of patients, a direct correlation was found between the duration of diabetes mellitus and the level of glucosuria, while in other studies, an increase in the renal threshold for glucose excretion was found as the disease duration increases [21].

According to our data, in very elderly patients, inverse correlations were observed between all indicators of glucose metabolism and age of diabetes mellitus onset. This is consistent with other studies showing that the later the onset of diabetes mellitus, the less severe it is. This applies to both the glucose control and the frequency and severity of diabetes mellitus complications [13] [14] [15] [16] [22] [23]. These data correspond to the results of our comparative analysis of very elderly patients and patients under 70 years of age with diabetes mellitus. In very elderly patients, all glycemic parameters were lower than in younger patients, and the frequency of glucosuria was significantly lower. At the same time, obesity and higher indicators of body mass index, triglyceride concentration and atherogenic index were more often registered in patients under 70 years of age. The HDL-cholesterol level was significantly lower in younger diabetic patients than in very elderly patients. 
According to other authors, elderly diabetic patients also have lower levels of hemoglobin A1c and blood glucose, body mass index and frequency of obesity, as well as less significant dyslipidemia than patients with an age of the disease onset less than 65 years [1] [14] [22]. However, our very elderly patients were found to have higher values of azotemia and a lower glomerular filtration rate, which can be explained by age-related decrease in renal function [16].

Despite the rather significant results obtained in this study, there are a number of limitations in this work. Unlike most similar studies, which included younger patients, our study was performed with the participation of a special population of patients-people of very advanced age who suffered from multiple pathological conditions, that could affect the study results. The cognitive characteristics of the studied group of patients did not allow us to adequately assess the role of lifestyle, diet and other factors that could affect the diabetes mellitus course. One of the limitations of our study is its cross-sectional rather than prospective nature, and therefore it was impossible to study the dynamics of the diabetes mellitus course with the further aging of patients.

\section{Conclusion}

The study results indicate that diabetes mellitus is often diagnosed in very elderly patients with chronic coronary artery disease. In very elderly diabetic patients, lower values of blood glucose, hemoglobin A1c and glucosuria are registered, compared with younger patients. In addition, dyslipidemia and obesity are less significant in older patients. Despite some limitations, this study established the approximate prevalence of diabetes mellitus and identified a number of diabetes mellitus features in very elderly Russian patients with coronary artery disease. It is advisable to further investigate the diabetes mellitus features in very elderly patients and centenarians with a large sample of individuals.

\section{Conflicts of Interest}

The authors declare no conflicts of interest regarding the publication of this paper.

\section{References}

[1] American Diabetes Association (2018) Classification and Diagnosis of Diabetes: Standards of Medical Care in Diabetes-2018. Diabetes Care, 41, S13-S27. https://doi.org/10.2337/dc18-S002

[2] Chentli, F., Azzoug, S. and Mahgoun, S. (2015) Diabetes Mellitus in Elderly. Indian JEndocrinol Metab, 19, 744-752. https://doi.org/10.4103/2230-8210.167553

[3] Wannamethee, S.G., Welsh, P., Papacosta, O., Lennon, L., Whincup, P.H. and Sattar, N. (2015) Copeptin, Insulin Resistance and Risk of Incident Diabetes in Older Men. JClin Endocrinol Metab, 100, 3332-3339.

https://doi.org/10.1210/JC.2015-2362

[4] Li, Y.X. and Zhou, L. (2015) Vitamin D Deficiency, Obesity and Diabetes. Cell Mol Biol (Noisy-le-grand), 61, 35-38. 
[5] Cândido, F.G. and Bressan, J. (2014) Vitamin D: Link between Osteoporosis, Obesity, and Diabetes? Int J Mol Sci, 15, 6569-6591. https://doi.org/10.3390/ijms15046569

[6] Dasgupta, A., Sarma, D. and Saikia, U.K. (2012) Hypomagnesemia in Type 2 Diabetes Mellitus. Indian JEndocrinol Metab, 16, 1000-1003.

https://doi.org/10.4103/2230-8210.103020

[7] International Diabetes Federation (2019) IDF Diabetes Atlas. 9th Edition, Brussels, Belgium. https://www.diabetesatlas.org

[8] Caspersen, C.J., Thomas, G.D., Boseman, L.A., Beckles, G.L. and Albright, A.L. (2012) Aging, Diabetes, and the Public Health System in the United States. Am J Public Health, 102, 1482-1497. https://doi.org/10.2105/AJPH.2011.300616

[9] American Diabetic Association (2018) Older Adults: Standards of Medical Care in Diabetes -2018. Diabetes Care, 41, S119-S125. https://doi.org/10.2337/dc18-S011

[10] Chia, C.W., Egan, J.M. and Ferrucci, L. (2018) Age-Related Changes in Glucose Metabolism, Hyperglycemia, and Cardiovascular Risk. Circulation Research, 123, 886-904. https://doi.org/10.1161/CIRCRESAHA.118.312806

[11] Kalyani, R.R., Golden, S.H. and Cefalu, W.T. (2017) Diabetes and Aging: Unique Considerations and Goals of Care. Diabetes Care, 40, 440-443. https://doi.org/10.2337/dci17-0005

[12] Huang, E.S., Liu, J.Y., Moffet, H.H., John, P.M. and Karter, A.J. (2011) Glycemic Control, Complications, and Death in Older Diabetic Patients: The Diabetes and Aging Study. Diabetes Care, 34, 1329-1336. https://doi.org/10.2337/dc10-2377

[13] Li, L., Ji, L., Guo, X., et al. (2015) Prevalence of Microvascular Diseases among Tertiary Care Chinese with Early versus Late Onset of Type 2 Diabetes. J Diabetes Complications, 29, 32-37. https://doi.org/10.1016/j.jdiacomp.2014.08.010

[14] Lv, F., Cai, X., Hu, D., et al. (2019) Characteristics of Newly Diagnosed Type 2 Diabetes in Chinese Older Adults: A National Prospective Cohort Study. J Diabetes Res, 2019, Article ID: 5631620. https://doi.org/10.1155/2019/5631620

[15] Sazlina, S.G., Mastura, I., Ahmad, Z., et al. (2014) Control of Glycemia and Other Cardiovascular Disease Risk Factors in Older Adults with Type 2 Diabetes Mellitus: Data from the Adult Diabetes Control and Management. Geriatr Gerontol Int, 14, 130-137. https://doi.org/10.1111/ggi.12070

[16] Steinarsson, A.O., Rawshani, A., Gudbjörnsdottir, S., Franzen, S., Svensson, A.-M. and Sattar, N. (2018) Short-term Progression of Cardiometabolic Risk Factors in Relation to Age at Type 2 Diabetes Diagnosis: a Longitudinal Observational Study of 100,606 Individuals from the Swedish National Diabetes Register. Diabetologia, 61, 599-606. https://doi.org/10.1007/s00125-017-4532-8

[17] Ma, Q., Liu, H., Xiang, G., Shan, W. and Xing, W. (2016) Association between Glycated Hemoglobin A1c Levels with Age and Gender in Chinese Adults with no Prior Diagnosis of Diabetes Mellitus. Biomed Rep, 4, 737-740. https://doi.org/10.3892/br.2016.643

[18] Wu, L., Lin, H., Gao, J., et al. (2017) Effect of Age on the Diagnostic Efficiency of $\mathrm{HbA1c}$ for Diabetes in a Chinese Middle-Aged and Elderly Population: The Shanghai Changfeng Study. PLOS ONE, 12, e0184607. https://doi.org/10.1371/journal.pone.0184607

[19] Juarez, D.T., Sentel, T., Tokumaru, S., Goo, R., Davis, J.W. and Mau, M.M. (2012) Factors Associated with Poor Glycemic Control or Wide Glycemic Variability among Diabetes Patients in Hawaii, 2006-2009. Prev Chronic Dis, 9, 120065. https://doi.org/10.5888/pcd9.120065 
[20] Al-Akour, N.A., Khader, Y.S. and Alaoui, A.M. (2011) Glycemic Control and Its Determinants among Patients with Type 2 Diabetes Mellitus Attending a Teaching Hospital. J Diabetes Metab, 2, 4-9.

[21] Yue, X.D., Wang, J.Y., Zhang, X.R., et al. (2017) Characteristics and Impact Factors of Renal Threshold for Glucose Excretion in Patients with Type 2 Diabetes Mellitus. J Korean Med Sci., 32, 621-627. https://doi.org/10.3346/jkms.2017.32.4.621

[22] Yotsapon, T., Sirinate, K., Ekgaluk, W., et al. (2016) Clinical Characteristics and Outcomes of the Oldest Old People with Type 2 Diabetes-Perspective from a Tertiary Diabetes Center in Thailand. BMC Endocr Disord, $16,30$. https://doi.org/10.1186/s12902-016-0115-9

[23] Motta, M., Bennati, E., Capri, M., Ferlito, L. and Malaguarnera, M. (2008) Diabetes Mellitus in the Extreme Longevity. Exp Gerontol, 43, 102-105.

https://doi.org/10.1016/j.exger.2007.06.012 